\title{
Effect of Complementary Feeding Practices and Nutritional status of Children (6-23 months) in Tamang Community, Ambhanjyang VDC of Makwanpur
}

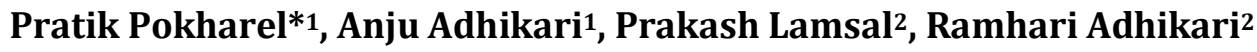 \\ College of Applied Food \& Dairy Technology \\ Kathmandu, Nepal
}

${ }^{1}$ Food and Agriculture Organization of the United Nations, Jajarkot, Nepal

${ }_{1}^{1}$ UNICEF, Nepālganj Zone Office, Nepal

${ }^{2}$ CAFODAT, Baneshwor, Kathmandu

${ }^{2}$ CAFODAT College, Baneshwor, Kathmandu

\section{ABSTRACT}

Background and Objectives: The aim of the paper was designed to know the relationship between complementary feeding, nutritional knowledge and behavior of mothers (IYCF practices) and nutritional status of children less than two years of age at Ambhanjyang Village Development Committee (VDC) of Makwanpur district.

Material and Methods: The study was conducted in aforesaid VDC of Makwanpur districts with a total of 120 samples. The questionnaire used consisted of socio-demographic information, health profile, dietary behavior of the child such as amount of feeding, frequency of feeding, diversified food and attitude statements of mothers regarding nutritional knowledge. The nutritional status of the child was assessed on the basis of anthropometric measurements weight and height.

Results: In this survey, 21.2 percent of the children were found to be moderately underweight while 5.8 percent of the children were severely underweight, 19.2 percent were moderately stunted while 15 percent were found severely stunted. Likewise, 10.8 percent of the children found moderately wasted and only 1 child was found to be severely wasted. No significant association was observed between various socio-economic factors, complementary feeding practices and nutritional status of a child.

Conclusion: The prevalence of under nutrition, stunting and inadequate complementary feeding practices was observed in the study sample. Although no significant association was observed between various socio-demographic factors and nutritional status of a child, there is an immediate requirement of healthy knowledge and change in behavior of mothers of children about complementary feeding practices to prevent the deteriorating nutritional status of child.

Key Words: Nutrition, complementary feeding, Exclusive breast feeding, Undernutrition

\section{INTRODUCTION}

As of 2015, 159 million of the children under the age of five were chronically malnourished underscoring a global health and makes economic development a challenge. For improving nutrition in 2012, 176 members of 
the World Health Assembly endorsed the first-ever global nutrition targets, focusing on six areas: stunting, anemia, low birth weight, childhood overweight, breastfeeding, and wasting $[1,2]$.

Malnutrition is responsible, directly or indirectly, for over half of all childhood deaths. About $45 \%$ of child mortality is associated with malnutrition [1]. Undernutrition remains the number one risk factor in sub-Saharan Africa and the fourth in South Asia [3]. After six months of age when breast milk alone is no longer sufficient to meet all the nutritional requirements and complementary feeding needs to be started, Infants and young children are at increased risk of malnutrition. The period of transition from exclusive breastfeeding to family foods, referred to as complementary feeding, covers a child from 6-23 months of age, and is a very vulnerable period. According to NDHS 2011, only $70 \%$ of the infants are exclusively breast feed and only $66 \%$ of the children from 6-23 months received solid, semi-solid or soft foods [4]. It is the time when malnutrition starts in many infants, contributing to the high prevalence of malnutrition in children less than two years of age. For proper growth and development of the children and appropriate diet is a critical important [5].

The first two years of life are a critical window for ensuring optimal child growth and development. Complementary feeding should be timely, meaning that all infants should start receiving foods in addition to breast milk from 6 months onwards. It should be adequate, meaning that the complementary foods should be given in amounts, frequency, and consistency and using a variety of foods to cover the nutritional needs of the growing child while maintaining breastfeeding [6].

Scientific evidence indicates that inappropriate complementary feeding practices can have profound consequences for the growth, development and survival of infants and children [7]. Nutritional deficiencies during this period can lead to impaired cognitive development, compromised educational achievement and low economic productivity which become difficult to reverse later in life [8]. The Infant and Young Child Feeding (IYCF) practices recommend that breastfed children age 6-23 months also be fed food from four or more other food groups and be fed a minimum number of times per day. In Nepal, only 25\% of the children age 6-23 months who receive food from four or more food groups ${ }^{4}$. Improving infant and young child feeding (IYCF) practices in children 0-23 months of age is therefore critical to improved nutrition, health and development [8].

The NDHS measures children's nutritional status by comparing height and weight measurements against an international reference standard. According to the 2011 survey, $41 \%$ of children under five are stunted, or too short for their age. This indicates chronic malnutrition. Stunting is more common in rural areas (41.8\%) than urban areas (26.7\%). Stunting is least common among children of more educated mothers and those from wealthier families. Stunting ranges from $42.1 \%$ in the hill and Terai $37.4 \%$ and in the mountain by $52.9 \%$. Wasting (too thin for height), which is a sign of acute malnutrition, is kind of stagnant for many years which is $10 \%$ in Nepal. Wasting ranges from $11.2 \%$ in Terai, $10.6 \%$ in the hill and $10.9 \%$ in the mountain region. 
Underweight, or too thin for age, is more common - 29\% of Nepalese children under age five are underweight. Wasting, stunting and underweight are also affected by different factors such as Gender, Areas of residence, wealth quintile, maternal education and ecological zones [4].

Good nutrition is a prerequisite for the national development of countries and for the well-being of individuals. Although problems related to poor nutrition affect the entire population, women and children are especially vulnerable because of their unique physiology and socioeconomic characteristics. As described by lancet series 2013, three causes of undernutrition such as: Immediate causes of undernutrition are inadequate dietary intake and disease. A child's dietary intake and exposure to disease are affected by underlying factors, including household food insecurity (lack of availability of, access to, and/or utilization of a diverse diet), inadequate care and feeding practices for children, unhealthy household and surrounding environments, and inaccessible and often inadequate health care. Basic causes of poor nutrition encompass the societal structures and processes that neglect human rights and perpetuate poverty, limiting or denying the access of vulnerable populations to essential resources. Social, economic, and political factors can have a long-term influence on maternal and childhood undernutrition. Moreover, chronic undernutrition can lead to poverty, creating a vicious cycle [1].

It is well recognized that children are a nutritionally vulnerable segment of population, who are also very susceptible to morbidity due to infections. Under-nutrition is associated with impaired immune function and consequent increased susceptibility to infections; infections aggravate under nutrition; if this vicious cycle continues it may result in death of the child [1].

Many parts of the country and communities remain unexplored. One of the unexplored communities is the Tamang community of the Makawanpur district, which constitutes $47.3 \%$ of the total district population, who mostly live in mountainous or hilly regions. According to National census its population is $1,179,145$. In size of population it is in Fifth position of caste and Third position in ethnic group of Nepal. There are 2,980 total households and total VDC's population is 14,274, male are 6,846 and female are 7,428. This Tamang community is one of the highly marginalized communities categorized by Nepal Federation of Indigenous Nationalities [9]. In this context, the present study focuses on determinants of complementary feeding and nutritional status of children age (6-23) months and an understanding of factors affecting nutritional status of these children.

\section{MATERIAL AND METHODS}

\section{Study Design and Locale}

This was a cross-sectional study carried out in Ambhanjyang VDC of Makwanpur district. Systematic sampling study design was selected. The samples were selected from the VDCs systematically as Ward no. 2, 5, and 8 respectively. Within the wards, convenience sampling was used to include the samples and was selected entirely on Tamang community only.

\section{Sampling Size and Sampling Method}

Sample size has been estimated using the following formula considering prevalence of wasted children to be $11 \%$ in Nepal [4]. We 
know wasting is generally result of a recent nutritional deficiency. The indicator of wasting may exhibit significant periodic shifts associated with changes in the accessibility of food or prevalence of diseases. Hence, wasting prevalence is taken into account as it indicates recent nutritional status of a child. [10]. Also, the prevalence of wasting shows a peak in second year of child's life as well [11].

$$
n=\frac{z^{2} P(1-P)}{d^{2}}
$$

where $n=$ sample size,

$Z=\mathrm{Z}$ statistic for a level of confidence (1.64 for $90 \%$ level of confidence)

$P=$ expected prevalence or proportion (here 0.11 )

And $d=$ precision (in proportion of one; if $5 \%$, $d=0.05$ ) [12].

Considering this a sample size of 105 has been computed, further, 15 percent margin for non-response has been added to it. Therefore, 120 under two children were enrolled for the study.

\section{Ethical Consideration}

Official letter from College of Applied Food and Dairy Technology was taken before conducting the research. Similarly approval from the concerned authorities for the study was also taken. Prior information about the study was given to the respondent and data was collected voluntarily after their consent. Personal identity of the respondent was maintained confidential. No omission, manipulation and correction of the actually collected data were done for the research.

\section{Inclusion Criteria of the Samples}

- Mothers were selected from Tamang ethnic group

- Children age between 6 - 23 months

- Children whose parents/care takers approved consent for participation in the study

\section{Exclusion Criteria of the Samples}

- Children aged less than 6 months and more than 23 months

- Children with congenital diseases, history of metabolic diseases, chronic diseases, physical and mental impairment that could influence their growth.

\section{Tools and Techniques}

Since data collection involved interaction with mothers of preschool children who had considerable low level of literacy, interview method was used for data collection. The information was elicited using a semistructured questionnaire during house to house visits as well as in FCHVs monthly meeting. Information of the following aspects was gathered.

\section{Dependent Variables:}

The dependent variables for this study are the anthropometric indices namely: height for age, which indicates the level of stunting; weight for age, this indicates the level of underweight; and weight for height which indicates the level of wasting.

\section{Independent Variables:}

Independent variables were identified using UNICEF's conceptual framework of 
malnutrition which states that causes of under nutrition can be classified as immediate (poor diet, disease); underlying (household food insecurity, inadequate care, unhygienic living condition and inadequate health service); and basic (socio-economic factors such as poverty, type of family, education level of family etc.)

The anthropometric measurements include assessment of:

- Weight of the subject

- Height of the subject

The nutritional status indicator of child was classified as per their $\mathrm{Z}$ score when compared with the WHO Growth Standards as shown in table 1. [13] questionnaire. Wherever applicable, observations were also made to obtain information or to cross- check the information provided by the mother. The data collection was done from December 2015January 2016 and the collected raw data were cleaned, coded and entered as soon as data was generated. The analysis of the data was done by applying Statistical Package for Social Scientist (SPSS) version 16. As per need of the study, recoding and transformation of data was performed. A $p$ value of $\leq 0.05$ was considered to be statistically significant. Cross tabulation was done for descriptive analysis of each of variable.

\section{RESULTS}

Characteristics of the study population

Table 1: The Z score classification for Weight-for-age, Height-for-age, and Weight for height
\begin{tabular}{|l|l|l|l|}
\hline Z Score Classification & Weight-for-age & Height-for-age & Weight for height \\
\hline$<-2$ SD & $\begin{array}{l}\text { Severely/ } \\
\text { moderately underweight }\end{array}$ & $\begin{array}{l}\text { Severely/ moderately } \\
\text { stunted }\end{array}$ & $\begin{array}{l}\text { Severely/ moderately } \\
\text { wasted }\end{array}$ \\
\hline -2 SD to 1 SD & Normal & Normal & Normal \\
\hline$>1$ SD & Overweight/ obese & Tall & Overweight/ Obese \\
\hline
\end{tabular}

\section{Data Collection and Analysis}

Data collection was performed by professional data collector. Before administering the questionnaire, it was pretested and suitably modified. List of children enrolled in each health care centre of Ambhanjyang VDC was taken and after considering the inclusion/exclusion criteria they were short listed for the study. A door to door visit was then made to the child's house and in PHC/ORC service as well as in HMGs monthly meeting. Subsequently, 2-3 home visits were made to obtain the desired information using the structured
One hundred and twenty children were present in the study among them 54 (45\%) were boys and 66 (55\%) were girls. The result is shown in Table 2.

Table 2: Distribution of Child according to Sex

\begin{tabular}{|l|c|}
\hline Sex of a child & Number (\%) \\
\hline Boys & $54(45)$ \\
\hline Girls & $66(55)$ \\
\hline Total & $120(100)$ \\
\hline
\end{tabular}

\section{Early Initiation of Breastfeeding Practice}

Figure 1 depicts poor knowledge and practice of mothers regarding early initiation of breastfeeding. Majority of mothers, 92 
(76.6\%) reported of initiation of breast feeding within 4 hour after child is born whereas only 21 (17.5\%) mothers reported of initiation of breast feeding within 1 hour after child born. feeding. Table 3 shows mothers knowledge regarding complementary foods. All mothers reported that they had knowledge about complementary feeding practices. Majority of the mothers $58.3 \%$ started complementary

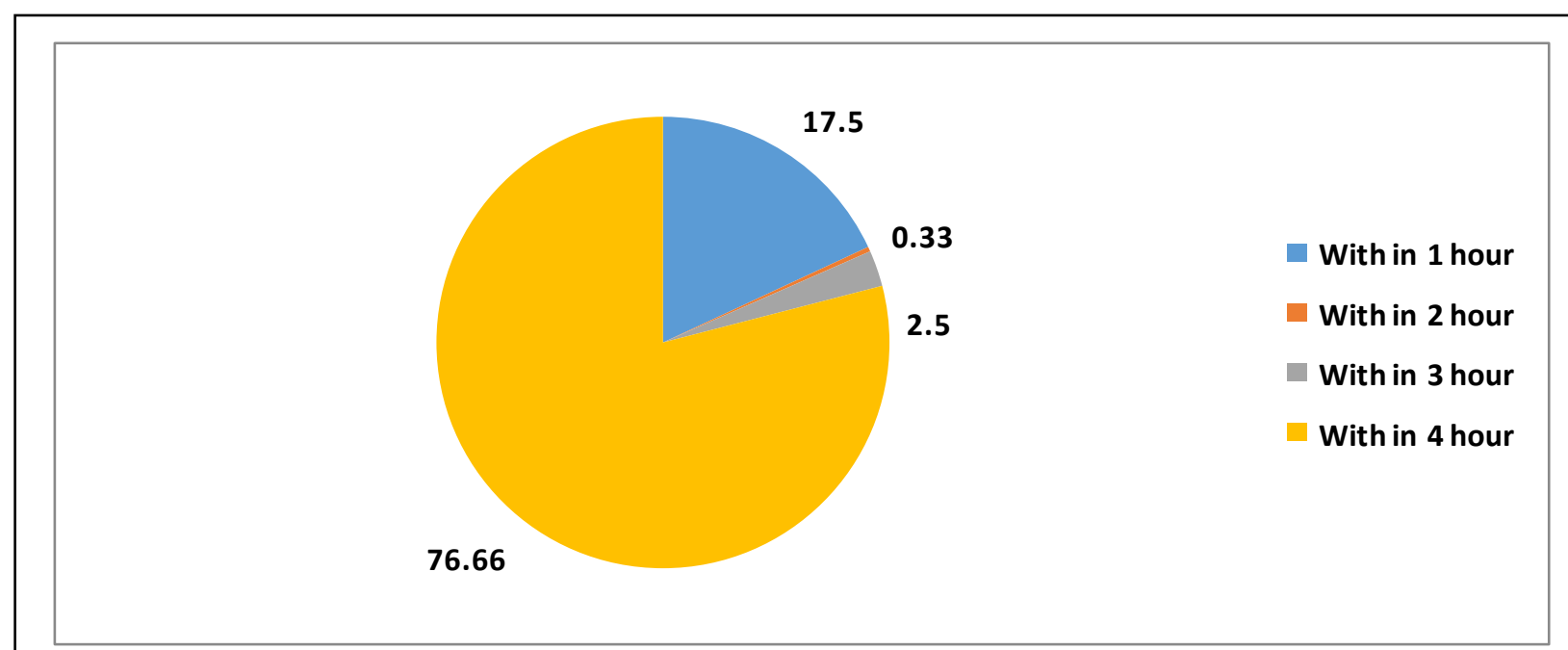

Figure 1: Practice of initiation of breast feeding after child is born in (\%)

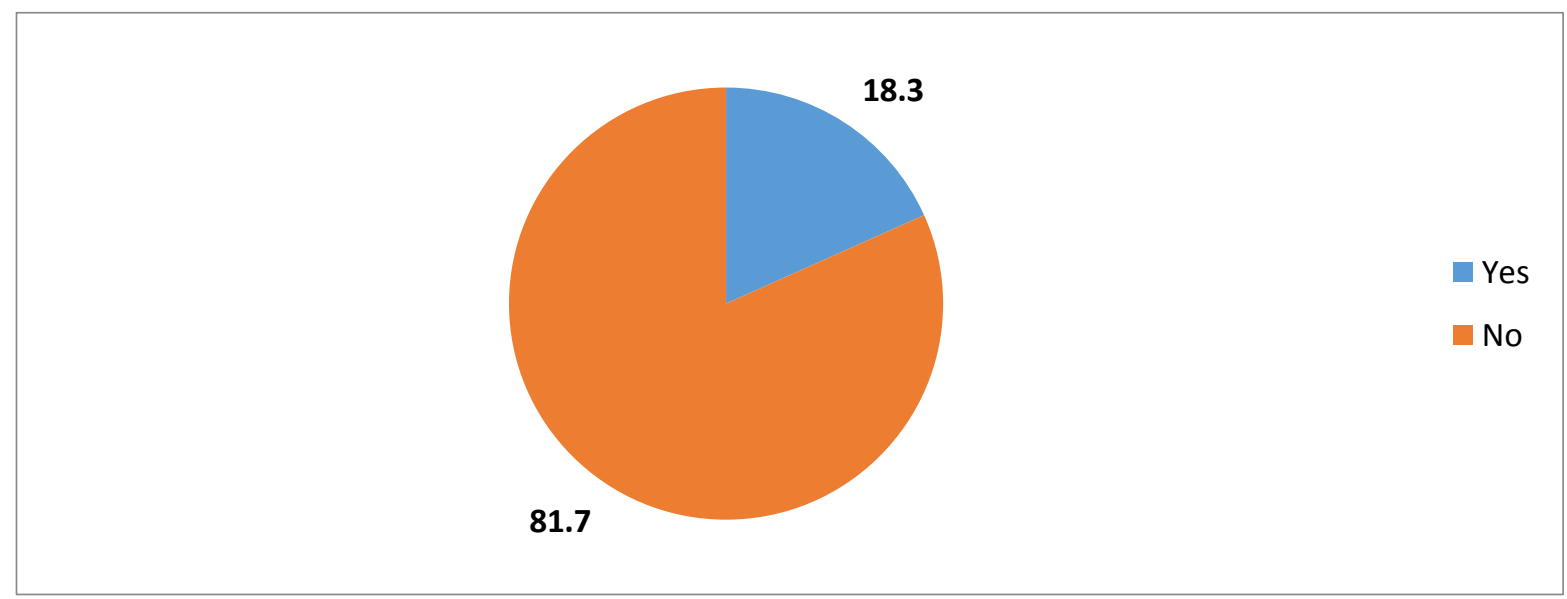

Figure 2: Classification of mothers on the basis of knowledge about exclusive breast feeding Complementary Feeding practices in (\%)

\section{Knowledge regarding Exclusive Breastfeeding}

Figure 2 shows poor knowledge among mothers regarding exclusive breastfeeding. $98(81.7 \%)$ mothers reported that they are not aware of exclusive breast feeding whereas only $22(18.3 \%)$ mother reported about having knowledge of exclusive breast feeding to their child after six months but $40.8 \%$ of the mothers reported of starting complementary feeding before six months. Table 4 shows common food group provided by mothers to their children during lunch time. Majority of the mothers $66.7 \%$ provided carbohydrate sources and $17.5 \%$ provided legume sources as a common food to a child. Only $15.8 \%$ provided common food as fruits, meat and milk sources to a child. Table 5 
Table 3: Distribution of Knowledge about Complementary Feeding Practices

\begin{tabular}{|c|c|}
\hline $\begin{array}{lr}\begin{array}{l}\text { Knowledge } \\
\text { complementary } \\
\text { practices }\end{array} & \begin{array}{r}\text { about } \\
\text { feeding }\end{array} \\
\end{array}$ & $\begin{array}{c}\text { Number } \\
(\%)\end{array}$ \\
\hline Yes & $120(100)$ \\
\hline No & - \\
\hline Total & $120(100)$ \\
\hline \multicolumn{2}{|l|}{ If yes when did you start } \\
\hline Before 6 month & $49(40.8)$ \\
\hline After 6 month & $70(58.3)$ \\
\hline Did not know & $1(0.83)$ \\
\hline Total & $120(100)$ \\
\hline
\end{tabular}

Table 4: Classification according to Food Groups consumed by Children

\begin{tabular}{|l|c|}
\hline $\begin{array}{l}\text { Common food during lunch } \\
\text { time }\end{array}$ & $\begin{array}{c}\text { Number } \\
(\mathbf{\% )}\end{array}$ \\
\hline Fruits & $9(7.5)$ \\
\hline Carbohydrates sources & $80(66.7)$ \\
\hline Legumes & $21(17.5)$ \\
\hline Meat and milk sources & $10(8.3)$ \\
\hline Total & $120(100)$ \\
\hline
\end{tabular}

Table 5: Classification according to viscosity of complementary food fed to children

\begin{tabular}{|l|c|}
\hline $\begin{array}{l}\text { Viscosity of complementary } \\
\text { food }\end{array}$ & $\begin{array}{c}\text { Number } \\
\text { (\%) }\end{array}$ \\
\hline Like honey & $13(10.8)$ \\
\hline Thin like water & $34(28.3)$ \\
\hline Semi solid & $73(60.8)$ \\
\hline Total & $120(100)$ \\
\hline
\end{tabular}

shows poor knowledge among mothers regarding consistency of complementary food provided to children. Most of the mothers $60.8 \%$ reported of providing semisolid viscous food whereas $28.3 \%$ of the mothers provide water consistency food to their child. Only 13 (10.8\%) mothers reported of providing viscous nutritious food like honey.

\section{Nutritional status of Child}

Figure 3 shows the nutritional status indicators of a child according to Weight for
Age, Height for Age and Weight for Height categorized according to WHO Child Growth Standards. 26 (21.7\%) children were found to be moderate underweight while 7 (5.8\%) children were severely underweight. The prevalence of moderate stunting was found to be in 23 (19.2\%) children while 18 (15\%) children were found to be severely stunted. Also, the prevalence of moderate wasting was found to be in $13(10.8 \%)$ children while only $1(0.8 \%)$ child was found to be severely wasted.

\section{Association between different Factors with Nutritional Status of Children}

Different factors like initiation of breastfeeding, initiation time of complementary feeding, mothers' knowledge about complementary feeding etc. was associated with nutritional status of child (weight for age, height for age and weight for height) but no such association was observed in this study.

To see the association between Weight for age and complementary feeding initiation before 6 six months of child, Chi-square test was performed. No significant association was observed as $\mathrm{p}$ value was observed to be greater than 0.05 as shown in table 6 and 7 . Similarly, there is no significant association between practice of complementary feeding initiation before 6 months and height for age of a child.

\section{DISCUSSION}

Children nutritional status is an image of their overall health. When children have adequate access to nutritious foods and proper health care from family, they achieve their adequate growth potential and become well nourished. WHO and UNICEF 


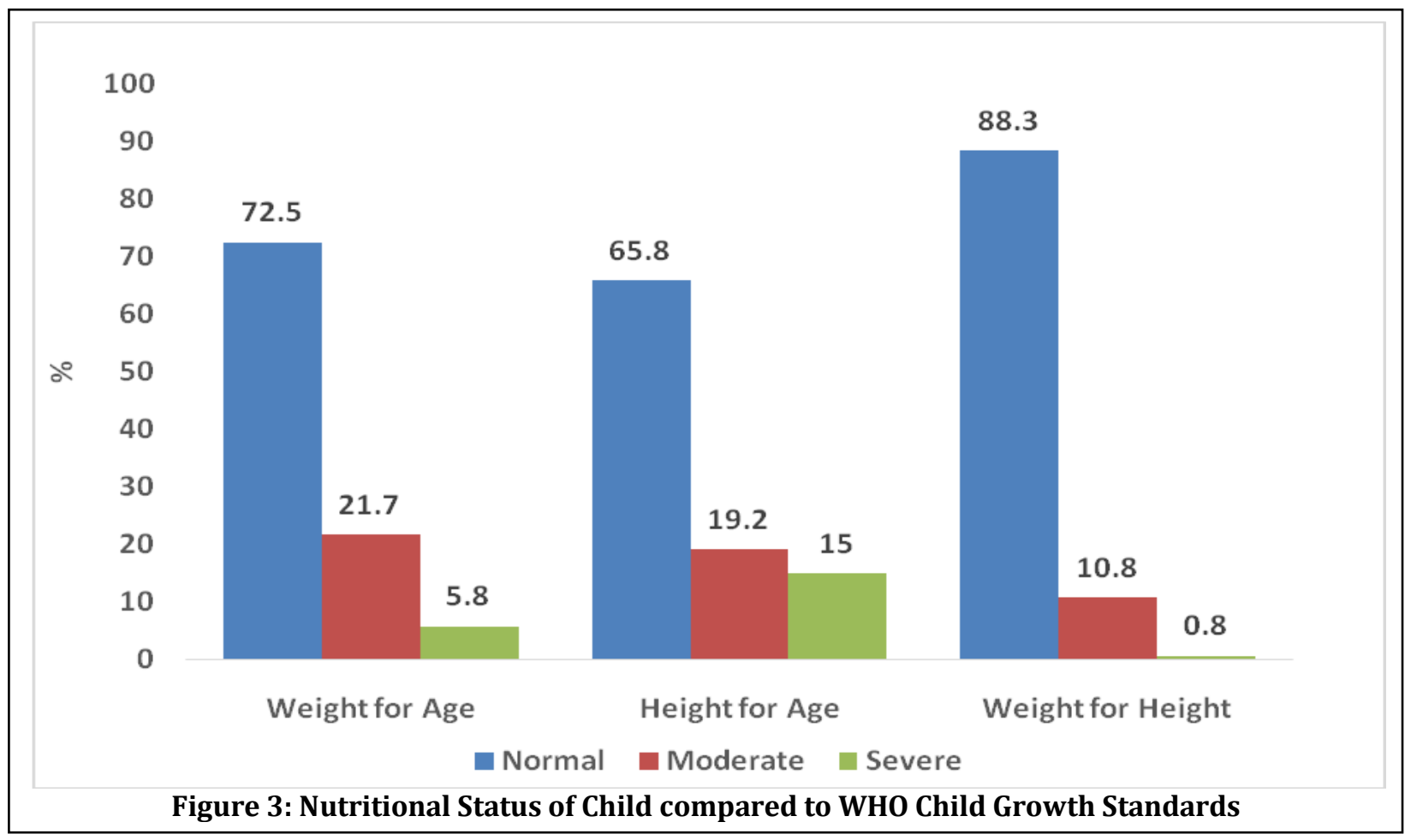

Table 6: Association between Weight of Child with the Initiation of Complementary Feeding Time

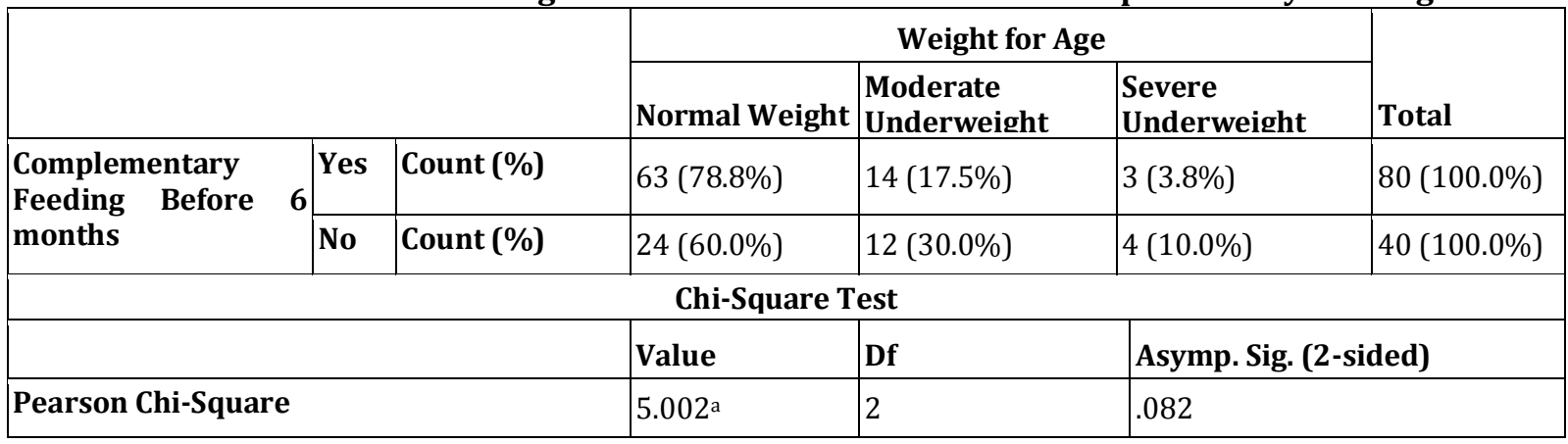

Table 7: Association between Height for Age with the Initiation of Complementary Feeding Time

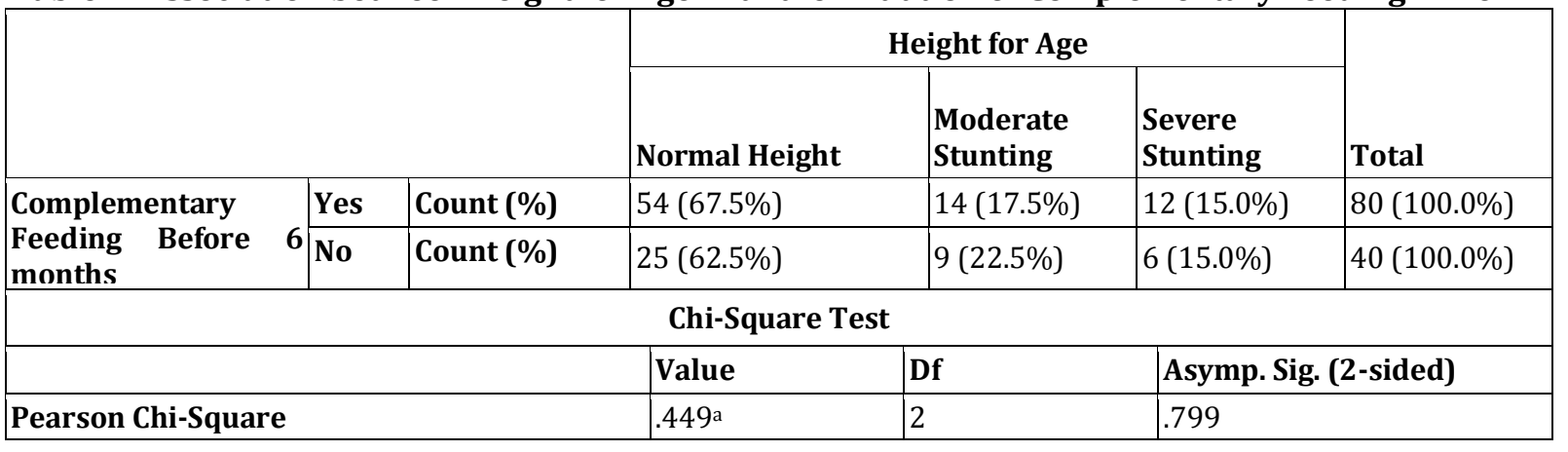

advocate that children be breastfed within one hour of birth, to be breastfed exclusively for the first six months of life, and continued to be breastfed for up to two years of age and beyond. Also, at six months, breastfeeding should be combined with nutrient dense and 
diverse, safe, age-appropriate feeding of solid, semi-solid and soft foods [10].

In this survey, $17.5 \%$ of mothers initiated breastfeeding within 1 hour of birth which is quite lower than figure of MICS study which shows $48.7 \%$ of mothers initiating breastfeeding within 1 hour of birth. It is evident from this survey that, majority of the mothers are found to be lacking in knowledge regarding exclusive breastfeeding. Only $22(18.3 \%)$ mothers knew the meaning of exclusive breastfeeding while others had no idea of it which could have impact in children nutritional status.

In this survey, $34(28.3 \%)$ of the mothers prepared water like complementary food for their baby. This tends to increase the amount of water consumed by a child causing fullness and hence lack of energy leading to growth faltering. Only, 13(10.8\%) mothers prepared honey like consistency food for their children which is appropriate for their child. Majority of the mothers, $70(58.3 \%)$ started complementary feeding to their child after six months which shows that the mother had knowledge about the time to start complementary feeding but 49 (40.8\%) mothers lacked knowledge on when to start complementary feeding and started it before 6 months.

Regarding nutritional status of child, 26 (21.2\%) children were found to be moderate underweight while $7(5.8 \%)$ children were severely underweight. A survey Demographic and Health Survey done in Nepal also showed that $28.8 \%$ of children were moderately underweight while $7.7 \%$ were found to be severely underweight among children below 5 years of age [4]. Also more recent study, Nepal Multiple Indicator Cluster Survey shows that, one in three children under five in Nepal are moderately or severely underweight (30\%) and 9\% are classified as severely underweight [10].

The prevalence of moderate stunting was found to be in $19.2 \%$ of the children while $15 \%$ of the children were found to be severely stunted. While Demographic and Health Survey of Nepal showed that $40.5 \%$ of children were moderately stunted while $16.2 \%$ of the child were severely stunted among children below 5 years of age [4]. Also, more than one-third (37\%) are moderately or severely stunted or too short for their age and $16 \%$ are severely stunted according to MICS study [10]. The prevalence of moderate wasting was found to be in $10.8 \%$ of the children while only 1 child was found to be severely wasted. NDHS 2011 showed that 10.9 percent of the children were moderately wasted while 2.6 percent of the children were severely wasted among children below 5 years of age [4].

No significant association was observed between various socio-economic factors, complementary feeding practices and nutritional status of a child. Although a study done in western Kenya showed that children who were introduced to complementary foods before 6 months had an increased risk of being underweight, no such association was observed in this study [14].

\section{CONCLUSION}

In addition to several nutrition related research being conducted in Nepal, this study also approves the prevalence of poor nutritional status in Tamang community of Aambhanjyang VDC, Makawanpur district of 
Nepal. Although several nutrition related community level programs are being launched in Nepal from different (non) government sectors, there is still more to be done to reduce the prevalence of undernutrition and to change the behavior of our community and mothers regarding proper nutrition and health care for their baby.

Lack of knowledge is a major hindrance in a developing country like Nepal. Although no significant association was observed in this study which might be due to limitation in sample size or other factors, there exists significant association between socioeconomic status, knowledge of community mothers, behavior and practice of nutrition related care with indicators of nutrition status. Hence, more rigorous programs and activities are required targeting mothers at community level to sensitize the importance of nutritional care and to uplift country's nutritional status.

\section{LIMITATION}

The samples were entirely from Tamang community of Aambhanjyang VDC of Makawanpur and cannot be solely generalized for other ethnic groups or other regions of Nepal.

\section{ACKNOWLEDGEMENT}

Authors wish heartfelt thanks to Sita BC for data collection support and College of Applied Food and Dairy Technology for creating environment of this study. Authors also thank all the mothers who participated in this study. Thanks also go to all others who have provided support for conduction of this study.

\section{AUTHOR'S CONTRIBUTION}

PP- Creation of first draft and reviewed critically, descriptive analysis, preparation of final manuscript; AA-creation of first draft and reviewed literatures, preparation of final manuscript; PL- data collection and drafting the study; RHA- revision of the draft and suggestions.

\section{SOURCE OF SUPPORT: None}

CONFLICT OF INTEREST: Authors state that there is no conflict of interest.

\section{REFERENCES}

1. Robert EB, Harold A, Zulfiqar AB et al. Maternal and child nutrition: building momentum for impact. Lancet 2013; 382: 372375

2. United Nations Children's Fund. UNICEF joint health and nutrition strategy for 20062015.NewYork 2005. Available at: http://www.unicef.org/about/execboard/files /068_health_and_nutrition_final_ODS.pdf

3. Victoria PW, William M, Ria L, Rob ED et al. Mortality trends and differentials in South Africa from 1997 to 2012: second National Burden of Disease Study. The Lancet Global Health 2016; 4: e642-e653.

4. Ministry of Health and Population (MOHP). National Demographic Health Survey 2011; Nepal, New ERA, and ICF International Inc. 2012.

5. Bhandari N, Mazumder S, Bahl R et al. An educational intervention to promote appropriate complementary feeding practices and physical growth in infants and young children in rural Haryana, India. The Journal of Nutrition 134, 2342-2348.

6. World Health Organization (WHO). Standards for Maternal and Neonatal Care. 2006; Geneva.

7. Butte NF, Hopkinson WW, Smith JM et al. Infant feeding mode affects early growth and body composition. Journal of Pediatrics 2000; 106: 1355-66.

8. Grantham-MG, Yin BC, Santiago C, et al. Developmental potential in the first 5 years for 
children in developing countries. Lancet 2007; 369: 60-70.

9. LawotiMahendra.Towards a democratic Nepal: Inclusive Political Institution for a multicultural society. New Delhi; 2012. P-94

10. Central Bureau of Statistics. Nepal Multiple Indicator Cluster Survey 2014, Final Report; Central Bureau of Statistics and UNICEF Nepal. 2015.

11. Global Database on Child Growth and Malnutrition. World Health Organization. Available at: http://www.who.int/nutgrowthdb/about/intr oduction/en/index2.html.

12. Naing L, Winn T, Rusli BN. Practical Issues in Calculating the Sample Size for Prevalence Studies, In: Archives of Orofacial Sciences, 2006. pp 9-14.

13. Global Database on Child Growth and Malnutrition. World Health Organization. Available at: http://www.who.int/nutgrowthdb/about/intr oduction/en/index5.html.

14. Bloss E, Wainaina F, Bailey BCPrevalence and predictors of underweight, stunting, and wasting among children aged 5 and under in Western Kenya, In: Journal of Tropical Medicine, 2004. pp 260 -270.

\section{Correspondence to:}

Pratik Pokharel

Food and Agriculture Organization of the United Nations, Jajarkot, Nepal

Email: Pokharelpratik1921@gmail.com. 